\title{
Translation and cross-cultural adaptation to Brazilian Portuguese of the Modified Tardieu Scale for muscle tone assessment among patients with spinal cord injury
}

Tradução e adaptação transcultural para o português do Brasil da Escala de Tardieu Modificada para avaliação do tônus muscular de pacientes com lesão medular

Patrícia Lima do Amaral SANTOS ${ }^{1}$, Roberta Caveiro GASPAR², Natália PADULA², Daniela Melo ALMEIDA', Mariana Callil VOOS 1,3

\begin{abstract}
Background: Assessment of muscle tone is of great importance for evaluating people with spinal injuries. Objective: To translate and adapt the Modified Tardieu Scale (MTS) to Brazilian Portuguese and validate its use for evaluating patients with spinal cord injury. Methods: The translation and adaptation of the "Escala de Tardieu Modificada" went through the steps of translation, translation synthesis, backtranslation and expert committee meeting. Two evaluators rated the tone of the elbow flexors/extensors, wrist extensors, knee flexors/ extensors and ankle plantar flexors of 51 patients with spinal cord injury. These patients were reevaluated after one week. Validation included intra and inter-rater reliability (ICC) and internal and external consistency. The Modified Ashworth Scale (MAS) was used in the evaluations, to investigate the correlations. Results: The Brazilian Portuguese version of the MTS is presented in this study. ICCs ranged from 0.60 to 0.99 (intra and inter-examiner) and there was a moderate to strong correlation with MAS. Conclusions: The MTS proved to be adequate for assessing the muscle tone of people with spinal cord injury in Brazil.
\end{abstract}

Keywords: spinal cord diseases; muscle spasticity; evaluation studies as topic; spinal cord; muscle tonus; spinal cord injuries.

RESUMO

Introdução: A avaliação do tônus muscular é de grande importância para a avaliação de pessoas com lesão muscular. Objetivo: Traduzir e adaptar para a língua portuguesa do Brasil a Modified Tardieu Scale (MTS) e validar seu uso para avaliação de pacientes com lesão medular. Métodos: A tradução e adaptação escala de Tardieu modificada (ETM) passou pelas etapas tradução, síntese de traduções, retrotradução e reunião do comitê de especialistas. Dois avaliadores classificaram o tônus dos músculos flexores/extensores de cotovelo, flexores de punho extensores/flexores de joelho e flexores plantares do tornozelo de 51 pacientes com lesão medular. Os pacientes foram reavaliados após uma semana. A validação incluiu a confiabilidade intra e interexaminadores (ICC), consistência interna e externa. A escala de Ashworth modificada (EAM) foi utilizada nas avaliações, para investigação das correlações. Resultados: A versão em língua portuguesa do Brasil é apresentada no presente estudo. Os ICC variaram de 0,60 a 0,99 (intra e interexaminador) e houve correlação moderada a forte com a EAM. Conclusões: A ETM mostrou-se adequa da para avaliação do tônus muscular de pessoas com lesão medular no Brasil.

Palavras-chave: doenças da medula espinhal; espasticidade muscular; estudos de avaliação como assunto; medula espinhal; tônus muscular; traumatismos da medula espinhal.

'Universidade de São Paulo, Faculdade de Medicina, Departamento de Neurologia, São Paulo SP, Brazil.

${ }^{2}$ Acreditando Centro de Recuperação Neuromotora Saúde e Bem-estar, São Paulo SP, Brazil.

${ }^{3}$ Pontifícia Universidade Católica de São Paulo, Faculdade de Ciências Humanas e da Saúde, Curso de Fisioterapia, São Paulo SP, Brazil.

Patrícia Lima do Amaral Santos (D) https://orcid.org/0000-0002-7356-1330; Roberta Caveiro Gaspar (D) https://orcid.org/0000-0001-6613-6785

Natália Padula (D) https://orcid.org/0000-0001-7604-9677; Daniela Melo Almeida (DD https://orcid.org/0000-0002-6444-8723; Mariana Callil Voos (D) https://orcid.org/0000-0001-6252-7287

Correspondence: Mariana Callil Voos; Email:mcvoos@pucsp.br.

Conflict of interest: There is no conflict of interest to declare.

Authors' contribution: PLAS: data collection, text writing, review; RCG, NP: data collection, review; DMA: data analysis, review; MCV: data analysis, text writing, statistical analysis, review.

Received on July 29, 2010; Received in its final form on October 16, 2020; Accepted on October 21, 2020. 


\section{INTRODUCTION}

Assessment of spasticity is one of the most important items of neurological physical therapy evaluation protocols. Patients experience loss of motor function due to spasticity, which is characterized by increased muscle tone. Spasticity depends on passive speed, resulting from hyperexcitability of the stretch reflex ${ }^{1,2}$. In patients with spinal cord injury, muscle atrophy and spasticity are the main motor symptoms. However, soft tissue retractions (regarding joints, ligaments and tendons) are also frequent, due to the absence of voluntary movements and to prolonged wheelchair use. These retractions can also affect assessment of muscle tone.

The Modified Ashworth Scale (MAS) is one of the most frequently used scales for classifying the muscle tone of people with spinal cord injury ${ }^{3}$. In MAS assessments, the therapist moves the limb through its full range of motion. If testing a muscle that primarily flexes a joint, the joint is placed in a maximally flexed position and moved to a position of maximal extension over one second (by counting "one thousand and one"). If testing a muscle that primarily extends a joint, the joint is placed in a maximally extended position and moved to a position of maximal flexion over one second (by counting "one thousand and one" while performing the complete range of motion) ${ }^{4}$. MAS classifies muscle groups with normal tone as zero (0). When a slight increase in muscle tone with minimal resistance at the end of the movement range is noted, the muscle group is scored as one (1). If a slight increase in muscle tone with minimal resistance in less than half of the movement range is observed, the muscle group is scored as one plus (1+). The score for a more markedly increased muscle tone over most of the arc of movement is two (2). When there is considerable resistance to passive stretching due to increased tone, the muscle group is scored as three (3). A score of four (4) is attributed when the affected segment is kept in rigid flexion or extension ${ }^{4,5}$.

Measurement of joint angles provides quantitative and objective variables, to complement the muscle tone classification $^{5}$. Through the Tardieu scale, calculation of the difference in joint range of motion between low and high passive stretching speeds is proposed, as a measurement of spasticity $^{1}$. Tardieu hypothesized that high speed would result in lower joint range of motion, compared with low passive stretching speed, due to the spastic reaction ${ }^{6}$. An extra category for tone classification was added, with a score of 5 , defined as immobile articulation, that is, impossibility of passive mobilization ${ }^{4}$. The scale was thus renamed the Modified Tardieu Scale (MTS) ${ }^{4,7}$.

The principles of the MTS were to (1) passively stretch a completely relaxed muscle, (2) maintain the position of the proximal segment during passive stretching, (3) identify the angle at which resistance (reflex muscle contraction) interrupted passive movement (stop angle) and (4) obtain the stop angle at two different speeds: slow and fast passive muscle stretching ${ }^{1,8}$. The proximal joint would need to be carefully stabilized because small variations in joint positioning could affect the degree of muscle stretching and change the angle of the spastic reaction during passive stretching ${ }^{1,9}$. The difference between the joint angles, in which these two muscle reactions occurred, was referred to as the spasticity angle ${ }^{10,11}$. Although Tardieu's studies on muscle tone started in the 1950s, the scale was officially recognized and named only in the late $1990 \mathrm{~s}^{1}$. In addition, many studies have been using this scale to evaluate patients with spinal cord injuries, stroke, cerebral palsy and traumatic brain lesions ${ }^{2,4,6,9-11}$. The aim of the present study was to translate, adapt and validate the MTS for assessing spasticity among individuals with spinal cord injury in Brazil.

\section{METHODS}

The steps of the present study were direct translation, translation synthesis, back-translation, expert committee meeting and final pre-test ${ }^{12}$. The translation was performed by two native Brazilians who were also fluent in English. One of the translators had prior knowledge about MTS objectives and concepts and the other did not. Both translators performed a semantic (and not just literal) translation, using words that had the same cultural context. These two versions were synthetized to produce the first translated version. Two other translators, fluent in both languages, but native in English, with no prior knowledge of spinal cord injury, translated the MTS back to English.

The translations were analyzed and compared at the expert committee meeting (which included four researchers and two translators). Semantic and cross-cultural equivalences between the translated and original scales were established. Two physical therapists then used the pre-test version to assess 51 patients with spinal cord injury. The physical therapists were experienced in spinal cord injury propaedeutics ( four to five years of experience). Subsequently, final adjustments were discussed at another meeting and the final version of the MTS in Brazilian Portuguese was determined.

Fifty-one patients at a neuromotor recovery clinic called "Acreditando Centro de Recuperação Neuromotora Saúde e Bem Estar" were included in this study. The inclusion criteria were that the subjects needed to have suffered a spinal cord injury and be aged between 18 and 60 years. Exclusion criteria were cognitive impairment (Mini-Mental State Examination score below 26), injuries below the level of the T11 vertebra (which would not show spasticity) and failure to sign the consent form (for any reason). This study was approved by the Ethics Committee of the University of São Paulo (number $2,394,446)$. The authors received formal consent from one of the MTS coauthors for this translation and validation process.

Spasticity was measured in the elbow flexors and extensors, wrist flexors, knee flexors and extensors and ankle 
plantar flexors. The evaluations of elbow flexors and extensors, wrist flexors, knee flexors and ankle plantar flexors were performed in the supine position. Knee extensors were tested in the prone position. Only the right side of each patient was evaluated. MAS was performed before MTS, with an interval of 30 minutes between one assessment and the other. This interval avoided possible changes in tone classification, both through passive mobilization and through memorization of the previous score by the examiner.

For the intra-examiner analysis, examiner 1 (P.L.A.S.) reassessed all participants using both MAS and MTS, seven days after the first evaluation. For the inter-examiner analysis, examiner 2 (R.C.G.) evaluated all the participants, without any knowledge about the previous scores. The tests were recorded using a smartphone. The images obtained were analyzed using the Kinovea software, experimental version 0.8.26-win32, licensed by GPLv2, for which access is free. The smartphone was positioned on a tripod, approximately $1.0 \mathrm{~m}$ from the floor and about $1.5 \mathrm{~m}$ from the stretcher. A five-centimeter square was marked on a mat for calibrating the films.

Markers were placed on the following: the greater tuberosity and lateral epicondyle of the humerus; the radial styloid process; the greater trochanter and lateral epicondyle of the femur; the fibular head; the lateral malleolus; and the proximal phalanx of the fifth toe. The Kinovea software divided each second into 25 frames. The knee and the foot angles were measured and tracked during high and low-speed passive mobilization. The full range of motion and the angle at which muscle resistance to passive stretching started were measured. MTS velocities were monitored by means of Kinovea. V1 (low-speed passive mobilization) was considered valid when the mean velocity ranged from 10 to 59 degrees per second. V2 (natural drop speed) was considered valid when the mean velocity ranged from 60 to 160 degrees per second. Because V2 reached a mean of 160 degrees per second in some patients with hypotonia, V3 (faster than the natural drop) was not considered safe for patients with spinal cord injury. The examiner gave a verbal signal ("now") every time resistance to passive stretching was noticed. The angle was measured from this first resistance to the maximum possible range of motion.

The validation of the MTS included test-retest analysis (intra-examiner and inter-examiner reliability), internal consistency and external consistency ${ }^{13}$. The test-retest analysis was described using intraclass correlation coefficients (ICC $)^{14}$. Based on the $95 \%$ confidence interval of the ICC estimate, values lower than 0.50 , between 0.50 and 0.75 , between 0.75 and 0.90 and greater than 0.90 were taken to be indicative of poor, moderate, good and excellent reliability, respectively ${ }^{14}$. The reliability was evaluated through the intraclass correlation coefficient (ICC) calculation. The ICC is one of the coefficients most used for estimating the stability of continuous variables, since it takes measurement errors into account.
The internal consistency reflected the homogeneity of the instrument and indicated whether the items measured the same characteristics. To analyze the internal consistency of the MTS, the correlations between the subitems were investigated ${ }^{15}$. External consistency (criterion validity) involves examining the relationship between the scores for a given instrument and some external criterion. This criterion should consist of a widely accepted measurement, with the same characteristics as the assessment instrument, i.e. an instrument or criterion that is considered to be the gold standard (MAS). External consistency was assessed by means of Spearman correlation coefficients, by testing the correlations between MTS and MAS ${ }^{16}$. Values close to 1.00 indicated strong correlation, while values close to 0.00 indicated that there was no correlation. Statistical analyses were performed using the Statistica 13.0 software. The significance level was set at alpha $<0.05$.

\section{RESULTS}

Table 1 shows the translated and adapted version of the Modified Tardieu Scale. The word "catch" has no literal correspondence in Brazilian Portuguese and was translated as "resistência", because it is more commonly associated with plastic hypertonia than with spastic hypertonia.

Table 2 shows the MTS and MAS scores. Elbow flexor angles during passive mobilization ranged from 90 to 150 degrees and elbow extensor angles ranged from 100 to 145 , and the total range of motion was considered to be 150 degrees. Wrist flexor angles ranged from 40 to 70 degrees. In lower-limb passive mobilization, knee extensor angles ranged from 60 to 150 degrees and knee flexor angles, from 84 to 140 . Ankle extensor angles ranged from 0 to 24 degrees (Table 2).

Table 3 shows the intra and inter-examiner reliability. The ICC ranged from 0.60 to 0.99 , and was classified from moderate to excellent (Table 3).

The internal consistency was calculated by means of inter-item correlation. The external consistency was tested by means of Spearman correlations, between MAS and MTS. The correlations ranged from 0.64 to 0.99 (Table 4).

\section{DISCUSSION}

The present study proposed the adaptation, translation and validation of the Modified Tardieu Scale (MTS) for use in Brazilian Portuguese, for patients with spinal cord injury. Kinematic analysis was used to measure the joint angles at which the examiner noticed the resistance of spasticity. The speeds at which the angles of muscle reaction were measured were digitally monitored. Although some studies had already investigated the relationships between MAS or MTS and electromyography ${ }^{10,11}$, no previous study measured and monitored 


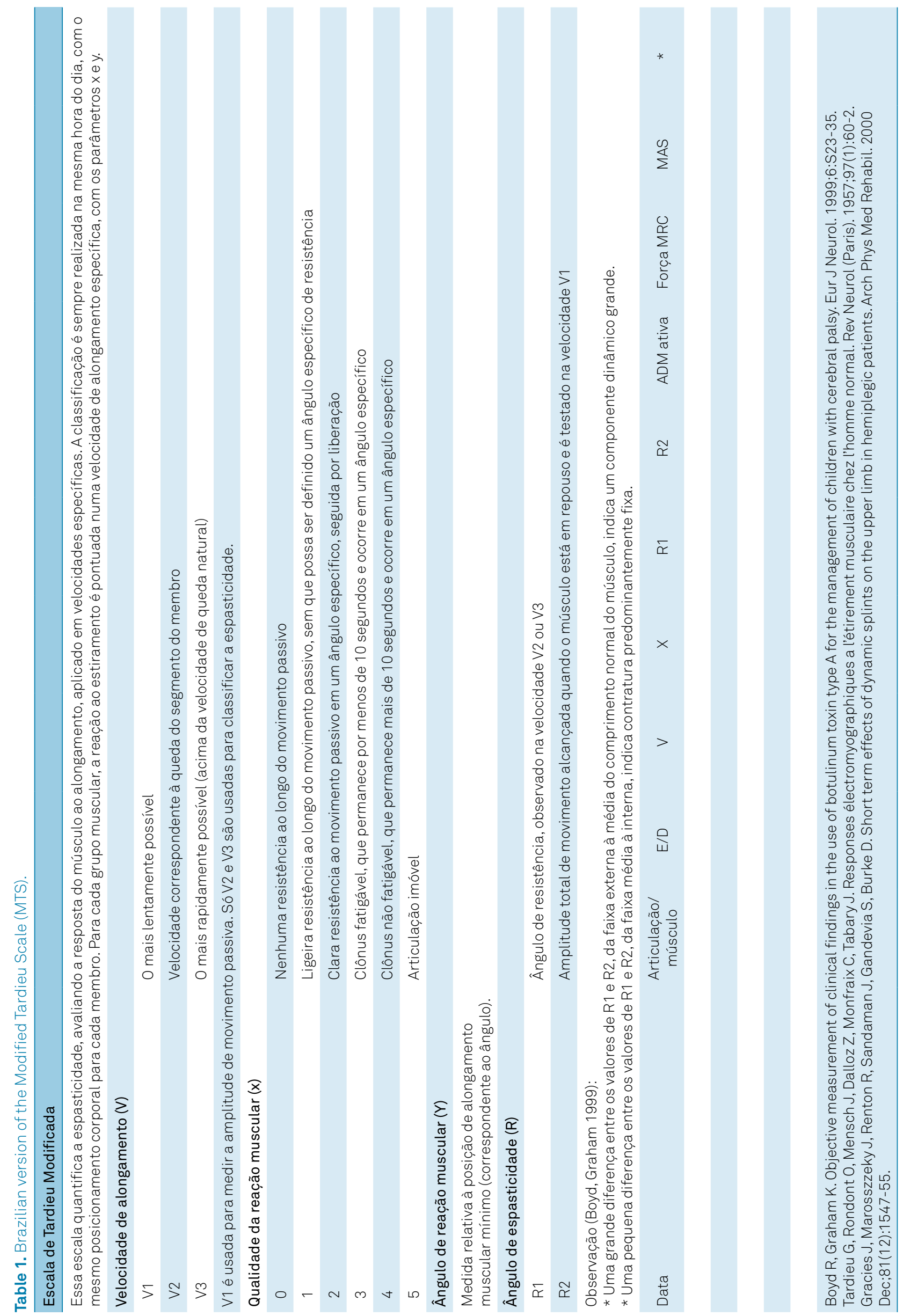




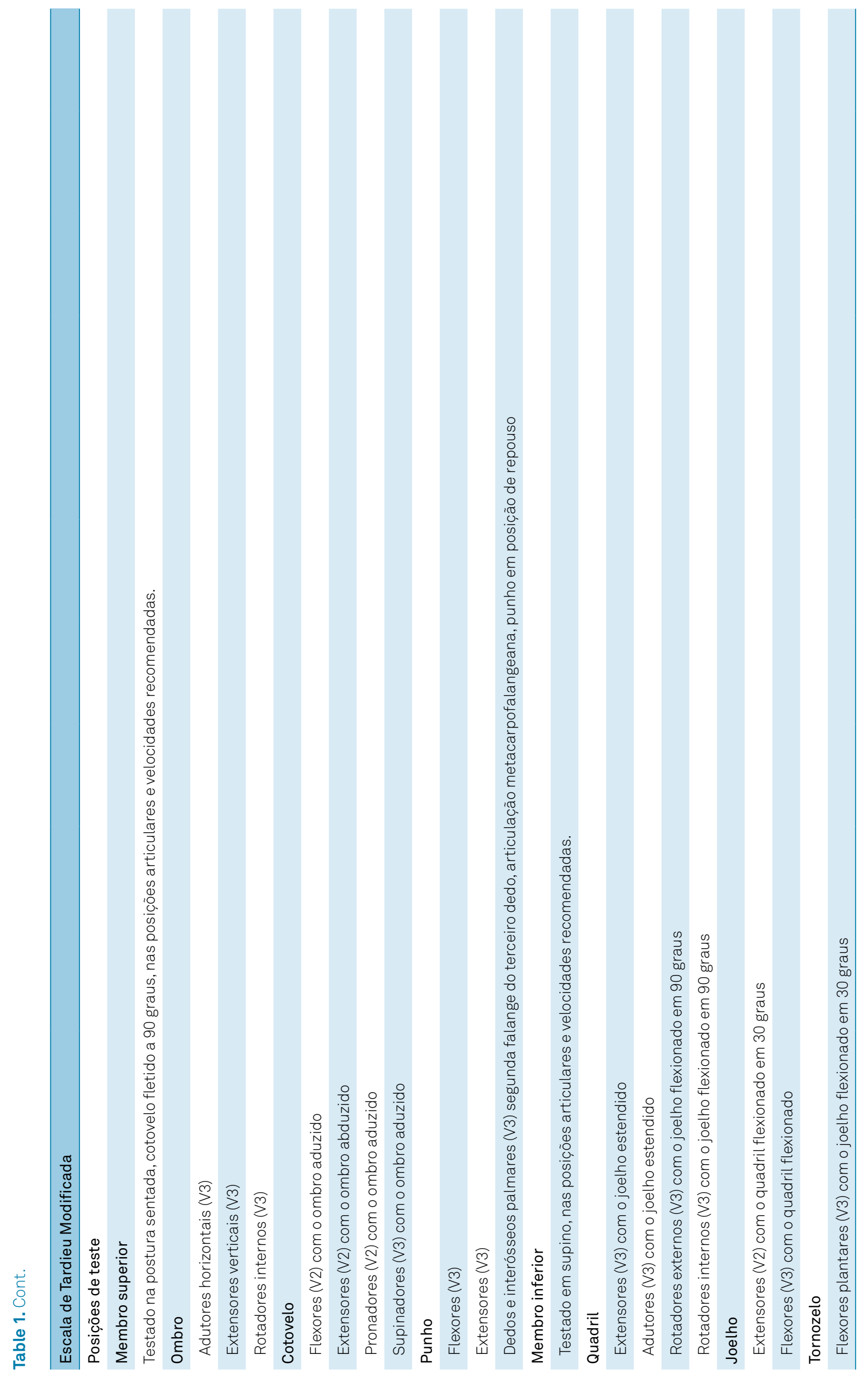


Table 2. Scores of Modified Tardieu Scale (MTS) and Modified Ashworth Scale (MAS).

\begin{tabular}{|c|c|c|c|c|c|}
\hline Muscle group & V1 angle (low speed) & $\begin{array}{l}\text { V2 angle (high } \\
\text { speed) }\end{array}$ & V1-V2 angle & ETM (or MTS) score & EAM (or MAS) score \\
\hline \multicolumn{6}{|c|}{ Elbow flexors (tested through elbow extension, considering 150 degrees as total range of motion) } \\
\hline Minimum & 100 & 90 & 10 & 0 & 0 \\
\hline Mean & 145 & 143 & 2 & 0.3 & 0.2 \\
\hline Median & 145 & 145 & 0 & 0 & 0 \\
\hline Maximum & 150 & 150 & 0 & 5 & 4 \\
\hline Standard deviation & 7.2 & 11.5 & 4.3 & 0.8 & 0.7 \\
\hline
\end{tabular}

Elbow extensors (tested through elbow flexion, considering 150 degrees as total range of motion)

$\begin{array}{lcccccc}\text { Minimum } & 110 & 100 & 10 & 0 & 0 \\ \text { Mean } & 142 & 142 & 0 & 0.2 & 0.1 \\ \text { Median } & 145 & 145 & 0 & 0 & 0 \\ \text { Maximum } & 145 & 145 & 0 & 1 & 1 \\ \text { Standard deviation } & 10.4 & 8.4 & 2 & 0.4 & 0.3\end{array}$

Wrist flexors (tested through elbow extension, considering 70 degrees as total range of motion)

$\begin{array}{llllcc}\text { Minimum } & 54 & 40 & 6 & 0 & 0 \\ \text { Mean } & 67 & 66 & 1 & 0.1 & 0.1 \\ \text { Median } & 70 & 70 & 0 & 0 & 1 \\ \text { Maximum } & 70 & 70 & 0 & 0.3 & 0.3\end{array}$

Knee extensors (tested through knee flexion, considering 140 degrees as total range of motion)

$\begin{array}{lccccc}\text { Minimum } & 90 & 60 & 30 & 0 & 0 \\ \text { Mean } & 130 & 128 & 2 & 0.6 & 0.7 \\ \text { Median } & 138 & 136 & 2 & 1 & 1 \\ \text { Maximum } & 150 & 150 & 0 & 2 & 2 \\ \text { Standard deviation } & 17.6 & 14.4 & 3.2 & 0.6 & 0.7\end{array}$

Knee flexors (tested through knee extension, considering 140 degrees as total range of motion)

$\begin{array}{lcccccc}\text { Minimum } & 90 & 84 & 6 & 0 & 0 \\ \text { Mean } & 135 & 134 & 1 & 0.6 & 0.8 \\ \text { Median } & 139 & 136 & 3 & 0 & 1 \\ \text { Maximum } & 140 & 140 & 0 & 5 & 4 \\ \text { Standard deviation } & 14.1 & 13.8 & 0.3 & 1 & 1\end{array}$

Ankle extensors (tested through ankle flexion, considering 20 degrees as total range of motion)

\begin{tabular}{lccccc} 
Minimum & 0 & 0 & 0 & 0 & 0 \\
Mean & 20 & 20 & 0 & 1.3 & 1.1 \\
Median & 19 & 18 & 1 & 1 & 1 \\
Maximum & 24 & 22 & 2 & 5 & 5 \\
Standard deviation & 2.0 & 1.8 & 0.2 & 1.1 & 1.1 \\
\hline
\end{tabular}

passive muscle stretching speed in spasticity assessments. In assessing the reliability of a scale, the experience and training of examiners and the standardization of guidelines for the evaluator are important factors. When used by well-trained and experienced examiners, the Portuguese-language version of the MTS (ETM) was found to have an intra-examiner reliability index that ranged from satisfactory to excellent.

Our results show the levels of intra-examiner agreement (test-retest analysis) for MAS and MTS. Although MAS is an easier tool to administer, MTS assesses the peripheral contributions to spasticity. Through use of kinematic analysis to monitor speed and range, MTS has become an even more reliable measurement of the degree of joint impairment, caused by changes in muscle tone. In a previous study among post stroke patients, the intraclass correlation coefficients ranged from 0.40 to 0.57 in the $\mathrm{MTS}^{17}$. In the present study, they ranged from 0.60 to 0.99 .

The use of technology to measure muscle reaction angles, by means of kinematic analysis, eliminates the need for a goniometer. In previous studies, in testing using a goniometer, 
Table 3. Intra and inter-examiner reliability of Modified Ashworth Scale (MAS) and Modified Tardieu Scale (MTS) angles and scores.

\begin{tabular}{|c|c|c|c|c|}
\hline INTRA-EXAMINER & Angle & Angle & Score & Score \\
\hline Muscle group & Low speed & High speed & MAS & MTS \\
\hline Knee extensors & 0.942 & 0.704 & 0.827 & 0.855 \\
\hline Knee flexors & 0.741 & 0.825 & 0.706 & 0.716 \\
\hline Ankle extensors & 0.979 & 0.972 & 0.864 & 0.813 \\
\hline Elbow flexors & 0.999 & 0.999 & 0.999 & 0.999 \\
\hline Elbow extensors & 0.999 & 0.999 & 0.999 & 0.999 \\
\hline Wrist flexors & 0.999 & 0.999 & 0.999 & 0.999 \\
\hline INTER-EXAMINER & Angle & Angle & Score & Score \\
\hline Muscle group & Low speed & High speed & MAS & MTS \\
\hline Knee extensors & 0.739 & 0.838 & 0.719 & 0.707 \\
\hline Knee flexors & 0.917 & 0.943 & 0.601 & 0.801 \\
\hline Ankle extensors & 0.961 & 0.941 & 0.607 & 0.815 \\
\hline Elbow flexors & 0.999 & 0.999 & 0.999 & 0.999 \\
\hline Elbow extensors & 0.999 & 0.999 & 0.999 & 0.999 \\
\hline Wrist flexors & 0.999 & 0.999 & 0.999 & 0.999 \\
\hline
\end{tabular}

MAS: Modified Ashworth Scale. MTS: Modified Tardieu Scale.

Table 4. Internal consistency calculated using inter-item correlation and external consistency tested using Spearman correlation between Modified Ashworth Scale (MAS) and Modified Tardieu Scale (MTS).

\begin{tabular}{lcc}
\hline Muscle group & Internal consistency & External consistency \\
\hline Knee extensors & 0.999 & 0.662 \\
Knee flexors & 0.999 & 0.641 \\
Ankle extensors & 0.983 & 0.841 \\
Elbow flexors & 0.775 & 0.995 \\
Elbow extensors & 0.999 & 0.745 \\
Wrist flexors & 0.925 & 0.999 \\
\hline
\end{tabular}

two highly synchronized examiners were needed ${ }^{2}$. One of the examiners had to stabilize, and passively mobilize the patient. The other examiner followed the movement simultaneously, to measure the angle at which joint resistance was perceived, using the goniometer. This immense demand for synchronicity between examiners created bias and restricted the use of the MTS in clinical practice and research. Use of free and accessible technology, such as Kinovea, will allow other professionals to monitor spasticity in a more specific way. The muscle reaction angle measurements of the present study showed moderate to excellent inter-examiner reliability, which justified use of the software, in association with the scale.

Our results showed that, although some patients had limited range of motion, most had normal range of motion in the upper limb joints. In the lower limbs, there were significant retractions, which increased the variability of the sample and its standard deviation. For this reason, the coefficients were higher in the analysis on variables of the upper limbs than of the lower limbs. The agreement levels in the MTS varied from moderate to excellent, and were higher in the scores for the flexor and extensor muscles of the elbow and wrist flexors.
Gracies et al. (2010) conducted a study using the MTS among patients with cerebral palsy ${ }^{18}$. They were able to successfully assess the spasticity of the elbow muscles and plantar flexors in children with cerebral palsy. However, they had poor inter-examiner reliability for measurements of knee spasticity angles, even after the examiners were trained. These findings agree with those of the present study, which found lower coefficients in knee and ankle testing. In addition, the positioning in a wheelchair favors a condition of muscle shortening, since patients spend most of the time in a sitting position, with 90 degrees of flexion of the hips and knees. The MTS may not be sensitive in the proximal muscle groups of the lower extremities and clonus may not be common in the proximal joint muscles.

In a study by Li, Wu and $\mathrm{Li}$ (2014), the reliability of the MAS and MTS was compared among patients with stroke ${ }^{19}$. They found similar results for inter-rater reliability of MAS scores. However, they concluded that the reliability of angle measurements using the MTS was insufficient. On the other hand, Akpinar et al. (2017) evaluated the reproducibility of the MAS and MTS among individuals with spinal cord injury $^{2}$. They obtained significant correlations between the 
MAS and MTS scores, with significantly higher reliability of the MTS than of the MAS in the lower-limb muscles. Those findings support the results from the present study and those of Mehrholz et al. (2005) ${ }^{4}$ and Waninge et al. $(2011)^{20}$, as these researchers showed higher reliability for the MTS than for the MAS.

The present study showed that the MAS and MTS are reliable tools for measuring spasticity among patients with spinal cord injury. In some measurements, the MTS was superior to the MAS, because it also indicated the effects of velocity and joint range of motion on spasticity. Therefore, the MTS can be considered to be a complementary tool in functional assessments on spinal cord injury. By comparing distinct speeds of passive stretching measurements, the MTS can differ orthopedic from neural limitations. Such information can be included in research protocols, and may help clinicians decide the best treatment options for patients with spinal cord injury.

In conclusion, the Modified Tardieu Scale showed inter and intra-examiner reliability and can be used to evaluate patients with spinal cord injury in Brazil.

\section{REFERENCES}

1. Morris SL, Williams G. A historical review of the evolution of the Tardieu Scale. Brain Inj. 2018;32(5):665-9. https://doi.org/10.1080/02 699052.2018 .1432890

2. Akpinar P, Atici A, Ozkan FU, Aktas I, Kulcu DG, Sari A, et al. Reliability of the Modified Ashworth Scale and Modified Tardieu Scale in patients with spinal cord injuries. Spinal Cord. 2017 Oct;55(10):9449. https://doi.org/10.1038/sc. 2017.48

3. Annaswamy T, Mallempati S, Allison SC, Abraham LD. Measurement of plantarflexor spasticity in traumatic brain injury: Correlational study of resistance torque compared with the modified Ashworth scale. Am J Phys Med Rehabil. 2007 May;86(5):404-11. https://doi. org/10.1097/PHM.0b013e31804a7d85

4. Mehrholz J, Wagner K, Meißner D, Grundmann K, Zange C, Koch $\mathrm{R}$, et al. Reliability of the modified tardieu scale and the modified ashworth scale in adult patients with severe brain injury: $A$ comparison study. Clin Rehabil. 2005 Oct;19(7):751-9. https://doi. org/10.1191/0269215505cr889oa

5. Mehrholz J, Major Y, Meißner D, Sandi-Gahun S, Koch R, Pohl M. The influence of contractures and variation in measurement stretching velocity on the reliability of the Modified Ashworth Scale in patients with severe brain injury. Clin Rehabil. 2005 Jan;19(1):63-72. https:// doi.org/10.1191/0269215505cr8240a

6. Banky M, Williams G. Tardieu Scale. J Physiother. 2017 Apr;63(2):126. https://doi.org/10.1016/j.jphys.2017.01.002

7. Gracies J. Evaluation de la spasticite. Mot cerebrale. 2001;22(1):1-15.

8. Glinsky J. Tardieu Scale.J Physiother. 2016 Oct;62(4):229. https://doi. org/10.1016/j.jphys.2016.07.007

9. Gracies J-M, Burke K, Clegg NJ, Browne R, Rushing C, Fehlings D, et al. Reliability of the Tardieu Scale for Assessing Spasticity in Children With Cerebral Palsy. Arch Phys Med Rehabil. 2010 Mar;91(3):421-8. https://doi.org/10.1016/j.apmr.2009.11.017

10. Singh P, Joshua A, Ganeshan S, Suresh S. Intra-rater reliability of the modified Tardieu scale to quantify spasticity in elbow flexors and ankle plantar flexors in adult stroke subjects. Ann Indian Acad Neurol. 2011 Jan;14(1):23-6. https://doi.org/10.4103/09722327.78045

11. Abolhasani H, Ansari NN, Naghdi S, Mansouri K, Ghotbi N, Hasson S. Comparing the validity of the Modified Modified Ashworth Scale
(MMAS) and the Modified Tardieu Scale (MTS) in the assessment of wrist flexor spasticity in patients with stroke: Protocol for a neurophysiological study. BMJ Open. 2012 Nov;2(6):e001394. https:// doi.org/10.1136/bmjopen-2012-001394

12. Beaton DE, Bombardier C, Guillemin F, Ferraz MB. Guidelines for the process of cross-cultural adaptation of self-report measures. Spine (Phila Pa 1976). 2000 Dec 15;25(24):3186-91. https://journals.Iww. com/spinejournal/citation/2000/12150/guidelines_for_the_process_ of_cross_cultural.14.aspx

13. Linting M, Meulman JJ, Groenen PJF, van der Kooij AJ. Nonlinear Principal Components Analysis: Introduction and Application. Psychol Methods. 2007 Sept;12(3):336-58. https://doi.org/10.1037/1082989X.12.3.336

14. Koo TK, Li MY. A Guideline of Selecting and Reporting Intraclass Correlation Coefficients for Reliability Research. J Chiropr Med. 2016 Jun;15(2):155-63. https://doi.org/10.1016/j.jcm.2016.02.012

15. Streiner DL. Starting at the beginning: an introction to coefficient alpha and internal consistency. J Pers Assess. 2003 Feb;80(1):99103. https://doi.org/10.1016/j.jclinepi.2005.10.015

16. de Vet HCW, Terwee CB, Knol DL, Bouter LM. When to use agreement versus reliability measures. J Clin Epidemiol. 2006 Oct;59(10):1033-9. https://doi.org/10.1016/j.jclinepi.2005.10.015

17. Ansari NN, Naghdi S, Hasson S, Rastgoo M, Amini M, Forogh B. Clinical assessment of ankle plantarflexor spasticity in adult patients after stroke: Inter-and intra-rater reliability of the Modified Tardieu Scale. Brain Inj. 2013;27(5):605-12. https://doi.org/10.3109/0 2699052.2012.750744

18. Gracies JM. Coefficients of impairment in deforming spastic paresis. Ann Phys Rehabil Med. 2015 Jun;58(3):173-8. https://doi. org/10.1016/j.rehab.2015.04.004

19. Li F, Wu Y, Xiong L. Reliability of a new scale for measurement of spasticity in stroke patients. J Rehabil Med. 2014 Sept;46(8):746-53. https://doi.org/10.2340/16501977-1851

20. Waninge A, Rook RA, Dijkhuizen A, Gielen E, van der Schans CP. Feasibility, test-retest reliability, and interrater reliability of the Modified Ashworth Scale and Modified Tardieu Scale in persons with profound intellectual and multiple disabilities. Res Dev Disabil. 2011 Mar-Apr;32(2):613-20. https://doi.org/10.1016/j.ridd.2010.12.013 